BMJ Open

Diabetes

Research

\& Care

\section{Association of glucose variability at the last day of hospitalization with 30-day readmission in adults with diabetes}

To cite: Spanakis EK, Singh LG, Siddiqui T, et al. Association of glucose variability at the last day of hospitalization with 30-day readmission in adults with diabetes. BMJ Open Diab Res Care 2020;8:e000990. doi:10.1136/ bmjdrc-2019-000990

Received 19 October 2019 Revised 3 February 2020 Accepted 18 March 2020
Check for updates

(C) Author(s) (or their employer(s)) 2020. Re-use permitted under CC BY-NC. No commercial re-use. See rights and permissions. Published by BMJ.

For numbered affiliations see end of article.

Correspondence to Dr Elias K Spanakis; ispanakis@som.umaryland.edu

\section{ABSTRACT}

Objective To evaluate whether increased glucose variability (GV) during the last day of inpatient stay is associated with increased risk of 30-day readmission in patients with diabetes.

Research design and methods A comprehensive list of clinical, pharmacy and utilization files were obtained from the Veterans Affairs (VA) Central Data Warehouse to create a nationwide cohort including 1042150 admissions of patients with diabetes over a 14-year study observation period. Point-of-care glucose values during the last 24 hours of hospitalization were extracted to calculate GV (measured as SD and coefficient of variation (CV)). Admissions were divided into 10 categories defined by progressively increasing SD and CV. The primary outcome was 30-day readmission rate, adjusted for multiple covariates including demographics, comorbidities and hypoglycemia.

Results As GV increased, there was an overall increase in the 30-day readmission rate ratio. In the fully adjusted model, admissions with CV in the 5th-10th CV categories and admissions with SD in the 4th-10th categories had a statistically significant progressive increase in 30-day readmission rates, compared with admissions in the 1st (lowest) CV and SD categories. Admissions with the greatest CV and SD values (10th category) had the highest risk for readmission (rate ratio (RR): $1.08(95 \% \mathrm{Cl} 1.05$ to 1.10$), p<0.0001$ and RR: 1.11 (95\% Cl 1.09 to 1.14), $\mathrm{p}<0.0001$ for CV and SD, respectively).

Conclusions Patients with diabetes who exhibited higher degrees of GV on the final day of hospitalization had higher rates of 30-day readmission.

Trial registration number NCT03508934, NCT03877068.

\section{INTRODUCTION}

Hospital readmissions, a high-priority quality indicator for the healthcare delivery system, has remained an important quality metric due to the significant economic burden, high prevalence and preventability. ${ }^{1}$ The Centers for Medicare and Medicaid hospital readmissions reduction program penalizes hospitals with higher readmission rates by reducing payments. $^{23}$

Patients with diabetes mellitus (DM) have high 30-day readmission rates, ranging from

\section{Significance of this Study}

What is already known about this subject?

- Hospital readmissions represent a high-priority quality indicator for the healthcare delivery system.

- Increased glucose variability (GV) has been linked to adverse outcomes in the hospital, such as prolonged length of stay.

- Hypoglycemia in the last 24 hours of hospitalization has been associated with increased 30-day readmissions.

What are the new findings?

- Admissions of patients with diabetes mellitus with the highest GV in the last 24 hours of the inpatient stay were associated with an increase in 30-day readmission rate ratios.

- This association persisted even after adjustment of multiple covariates, including hypoglycemia in the last 24 hours of the inpatient stay.

How might these results change the focus of research or clinical practice?

- The observed association between increased GV in the last 24 hours of hospitalization with higher rates of 30-day readmission may reveal a potentially independent and modifiable factor to reduce hospital readmissions.

$14 \%$ to $26 \% .^{13-14}$ In both 2012 and 2017, an estimated US $\$ 123$ billion of healthcare costs incurred was attributed to the hospitalizations of patients with $\mathrm{DM},{ }^{15}{ }^{16}$ with 30 -day readmissions costs estimated at US $\$ 20$ billion. ${ }^{17}$ Therefore, identifying underlying causes and potentially modifiable risk factors for readmissions is imperative as it may improve quality of care and reduce the cost of inpatient care in patients with DM.

Numerous risk factors for hospital readmissions have been described in patients with DM, including burden of comorbidities, ethnic/ racial minority, hospital-related and socioeconomic factors, among others. ${ }^{117}$ However, there is limited data available regarding the 
impact of inpatient dysglycemia (defined as hyperglycemia, hypoglycemia and increased glucose variability) on readmission risk. Hyperglycemia at time of admission or 24 hours before admission ${ }^{10}$ and hypoglycemia during hospitalization have been associated with higher 30-day readmission rates. ${ }^{18}$

Glucose variability (GV), another marker of dysglycemia, refers to the magnitude of glucose fluctuations that occur around the mean glucose, and is increasingly considered as an indicator of poor glycemic control. ${ }^{1920}$ Increased GV and hyperglycemia are known to be associated with adverse outcomes presumed to be secondary to their impact on oxidative stress, ${ }^{191-23}$ neuronal damage, mitochondrial damage and coagulation activity. ${ }^{23}{ }^{24}$ Increased GV during hospitalization is associated with a higher risk for poor clinical outcomes in the non-critical care setting such as prolonged length of stay (LOS) and increased postdischarge mortality, ${ }^{19}$ as well as increased mortality in the intensive care unit (ICU) setting. ${ }^{22}$ There is presently no gold standard for measurement of $\mathrm{GV}^{22} 25$ and several indices have been described. ${ }^{22} 23$ The most widely used measure is $\mathrm{SD}^{22}$ along with the coefficient of variation (CV) another valid and frequently used measure for $\mathrm{GV}^{19}$

The majority of the published studies have examined the effect of glucose control during the entire hospital stay on adverse outcomes. There is limited information about the relationship between glucose control during the last day of hospitalization and the risk for readmission. In a nationwide cohort study, we examined 843978 admissions among patients with DM and we reported a strong association of lower glucose values during the last 24 hours of hospitalization with adverse clinical outcomes, including higher 30-day readmission rates. ${ }^{26}$

To our knowledge, no previous studies have examined the relationship between $\mathrm{GV}$ during the last day of the hospitalization and risk of hospital readmission in patients with DM. Therefore, we evaluated whether increased GV during the last 24 hours of hospitalization, a potentially modifiable risk factor, is associated with increased 30-day readmission rates.

\section{METHODS}

\section{Study overview and data sources}

This nationwide cohort study used data obtained from the Veterans Affairs (VA) health system of patients with DM admitted between January 1, 2000 and December 31, 2014. ${ }^{2627}$ The study ended in 2014, as this was the final year in which International Classification of Diseases (ICD)-9 codes were used. Data were obtained from the VA Central Data Warehouse, a national administrative data repository which stores comprehensive clinical, pharmacy and utilization records and VA Vital Status File for dates of death. ${ }^{27}$

The cohort was created by initially identifying all acute VA admissions among patients with DM. Patients with DM were identified by either the presence of $\geq 2$ ICD-9 codes during the past 2 years from an inpatient stay or outpatient visit on separate days and/or had prescriptions for DM within the current year. ${ }^{28}$ We excluded admissions (figure 1) to psychiatric or long-term care settings $(\mathrm{n}=273549)$ and admissions ending with transfer to a non-VA hospital $(\mathrm{n}=54992)$, as follow-up data were not available, admissions with LOS $\geq 30$ days $(\mathrm{n}=34006)$ or LOS $<1$ day $(\mathrm{n}=59474)$, and admissions with in-hospital deaths $(n=30603)$. We also excluded admissions where there were less than two glucose values (including only those with two or more glucose values) during the last 24 hours of the hospitalization, as neither SD or CV can be computed, and glucose values collected within 5 min of previous glucose values as previously described $(\mathrm{n}=772482) .{ }^{19}$

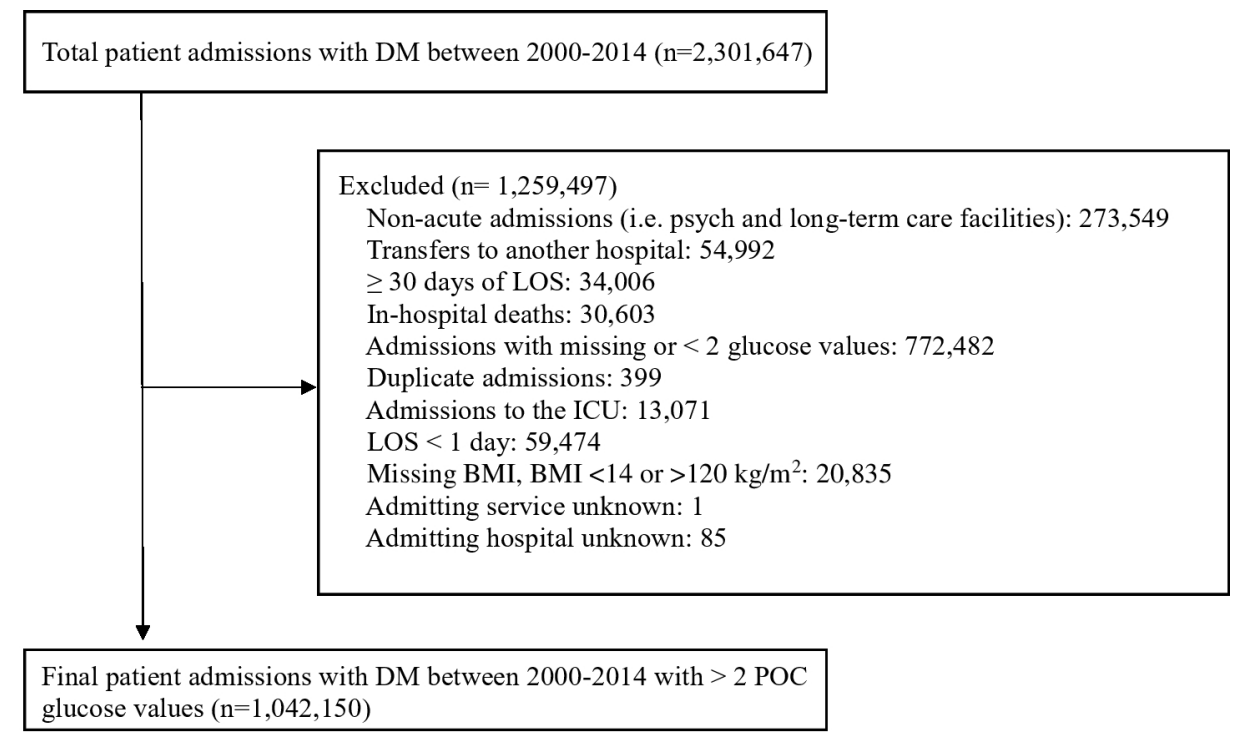

Figure 1 Study cohort creation flow diagram. BMI, body mass index; DM, diabetes mellitus; ICU, intensive care unit; LOS, length of stay; Psych, psychiatric. 
Additionally, 399 duplicate admissions were also excluded. Patients in the ICU were excluded as this represents a different population than those admitted to non-critical care settings $(n=13071) .{ }^{19}$ Finally, we excluded admissions with missing body mass index (BMI) or with BMI $<14 \mathrm{or}>120 \mathrm{~kg} / \mathrm{m}^{2} \quad(\mathrm{n}=20835)$, hospitalizations where it was not possible to determine the admitting service (medicine or surgery, $\mathrm{n}=1$ ) or the hospital where the patients were admitted $(\mathrm{n}=85) .{ }^{26}$ The final cohort sample used for analysis was 1042150 admissions.

\section{Covariates}

Independent variables analyzed for this study included age, gender, race, BMI, income, year of admission, admission source (whether patients were admitted from home or other facilities), admitting service (medicine or surgery), hemoglobin A1c (A1c) obtained 90 days prior to the admission, DM medications used during the last 24 hours of hospitalization and several comorbid conditions as previously defined by Elixhauser et al (table 1). ${ }^{29}$ Hypoglycemia in the hospital was defined as glucose values $<70 \mathrm{mg} / \mathrm{dL}^{30}{ }^{30}$ Length of hospital stay was calculated by subtracting the discharge day and time from the admission day and time, to ascertain the last 24 hours of the hospitalization.

\section{Exposures and outcomes}

Exposures of interest for this study were measures of GV, measured by the CV and SD. CV and SD were calculated from point-of-care (POC) glucose values measured (minimum $\geq 2$ values) during the last 24 hours of hospitalization. ${ }^{19}$ We divided $\mathrm{CV}$ and SD values into 10 different groups (deciles) with the 1st decile and the 10th decile having the lowest and the highest measurements, respectively. Our outcome measure was the 30-day readmission, defined as a rehospitalization which occurred within 30 days from the discharge date of the index admission. ${ }^{27} 31$ As patients with DM are at risk for multiple admissions (and therefore readmissions), ${ }^{32}$ we did not include the first readmission, as this approach would have led to exclusion of a significant number of rehospitalizations. All readmissions that occurred $>30$ days from the index hospitalization were considered new index admissions, as previously described..$^{2631}$

\section{Statistical methods}

The event rates were computed for every decile group of CV and SD. General estimating equations (GEE) with a Poisson distribution and an exchangeable covariance structure were used to compute adjusted rate ratios of the 30-day readmission while accounting for the correlation of repeated admissions obtained from the same patient and clustering in each center. ${ }^{33} 34$

We considered three models based on $\mathrm{CV}$ and SD deciles: (1) the minimally adjusted model, which controls for age, gender and race; (2) the second model which controls for all the variables collected (table 1), except for hypoglycemia (age, gender, including income, BMI, admission source (whether patients were admitted from home or other facilities), admitting service, DM medications, year of admission and multiple comorbidities); (3) the third model which controls for all the variables in the second model including also hypoglycemia. We did not adjust for A1c as only $35.3 \%$ of patient-admissions had an Alc obtained within 90 days of the hospitalization. Statistical analyses were performed using SAS software, V.9.4 (SAS Institute). Bonferroni corrected $\mathrm{p}$ values adjusting for multiple testing were used to compare the covariates among three CV categories based on the calculated CV values (admissions with CV deciles 1-4, CV deciles 5-7 and CV deciles 8-10) in table 1 . A two-tailed $p<0.05$ was considered to be statistically significant.

\section{RESULTS}

The final cohort included 1042150 unique admissions over the 14-year study observation period. In table 1 , we present baseline characteristics of the admissions of patients with DM, divided into three different categories based on the calculated $\mathrm{CV}$ values (admissions with CV 1-4, CV 5-7 and CV 8-10). Overall, the mean age of patients at admission was $66.5 \pm 10.8($ mean $\pm \mathrm{SD})$ years, with the majority being male $(97.2 \%)$ and Caucasian (71.64\%); $94.4 \%$ of them were admitted from home and were hospitalized under medicine service $(80.7 \%)$. The most common comorbid conditions included congestive heart failure (CHF (24.2\%)), cardiac arrhythmia $(22.9 \%)$, renal failure $(22.9 \%)$ and chronic obstructive pulmonary disease (COPD (21.8\%)). Overall median LOS was 3.9 days (IQR: 2.2-6.9) and 7.35\% of admissions of patients with DM exhibited hypoglycemia in the last 24 hours of hospitalizations. The mean number of POC glucose values during the last of the inpatient stay was $3.9 \pm 0.95$. Admissions among the three groups differed significantly in several of the covariates that we examined, an effect that can be secondary to the large sample size of our cohort. One notable observation however is that admissions in the 8-10 CV categories, which had the highest glucose variability measurements, had increased incidence of hypoglycemia (19.4\%) compared with admissions in the 5-7 CV (3.5\%) and 1-4 CV (1.3\%) categories (table 1).

In tables 2 and 3, we present 30-day readmission rate ratios (RR) of deciles of $\mathrm{CV}$ and $\mathrm{SD}$, using the first decile with the lowest variability as the reference group. For both $\mathrm{CV}$ and $\mathrm{SD}$, as glucose variability on the last day of admission increased, the 30-day readmission RR increased. For the CV analysis (table 2), after adjustment for age, gender and race (model 1), admissions that were in the 4th-10th CV deciles had an increased 30-day readmission rate compared with those admissions that were in the 1st CV category. Admissions with $\mathrm{CV}$ values in the 10th CV category had the highest 30-day readmission RR (1.23 (95\% CI 1.20 to 1.26$)$, $\mathrm{p}<0.0001)$. In contrast, admissions with $\mathrm{CV}$ values in the lowest deciles (CV 2-3) did not experience a statistically significant 


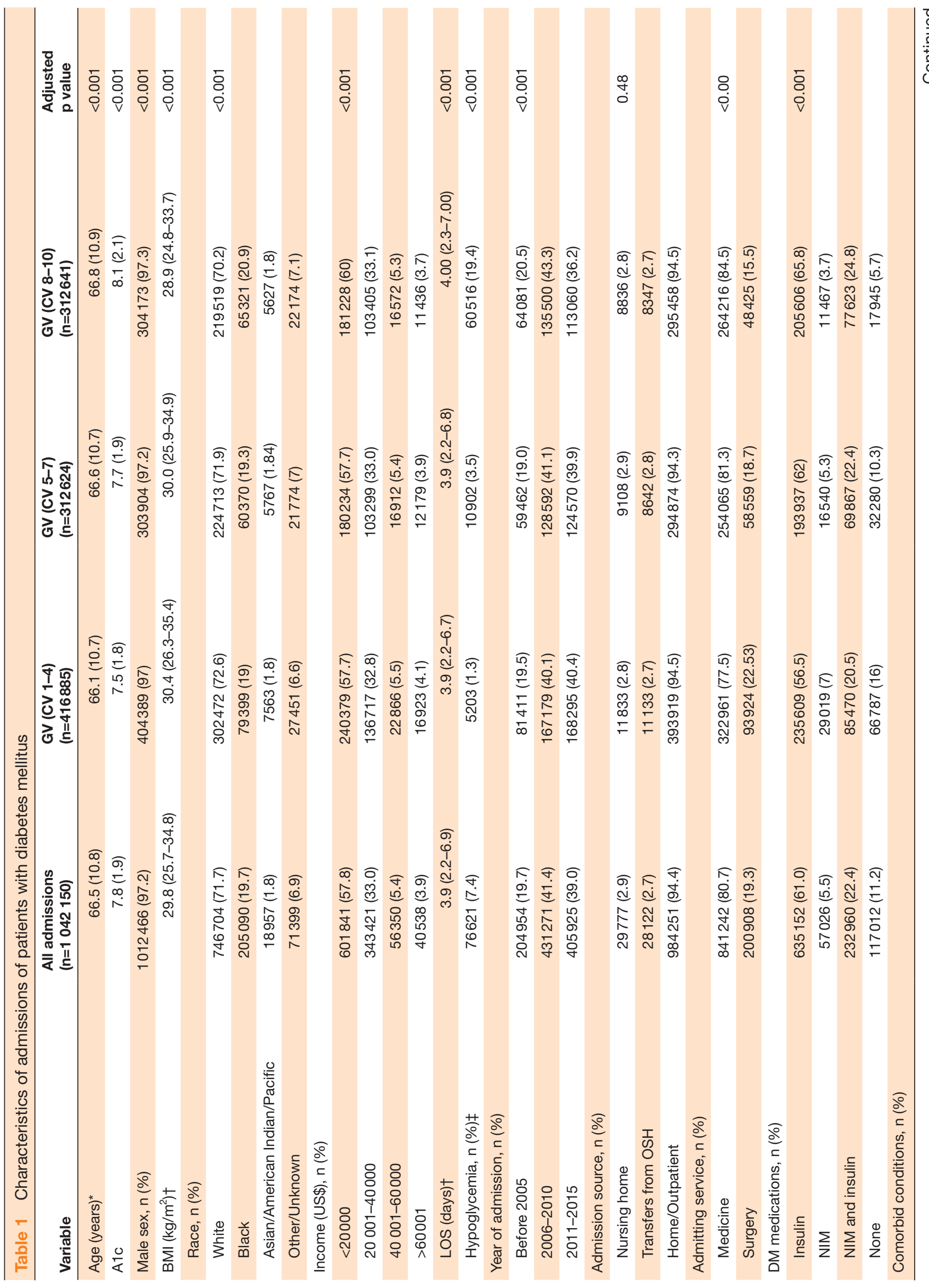

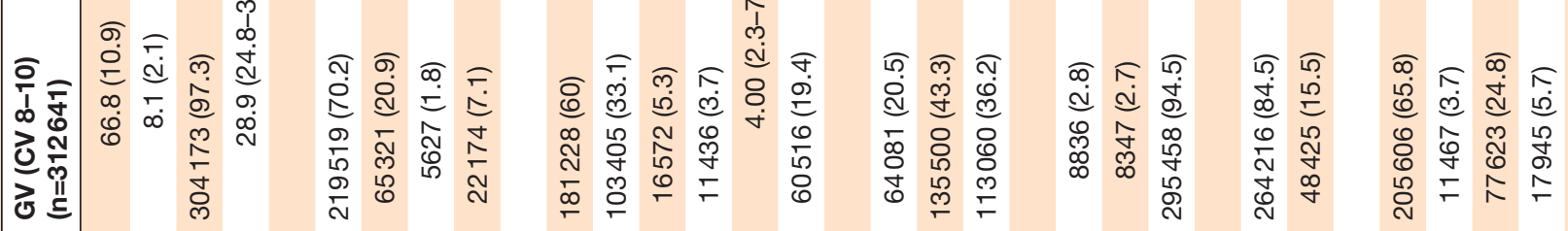




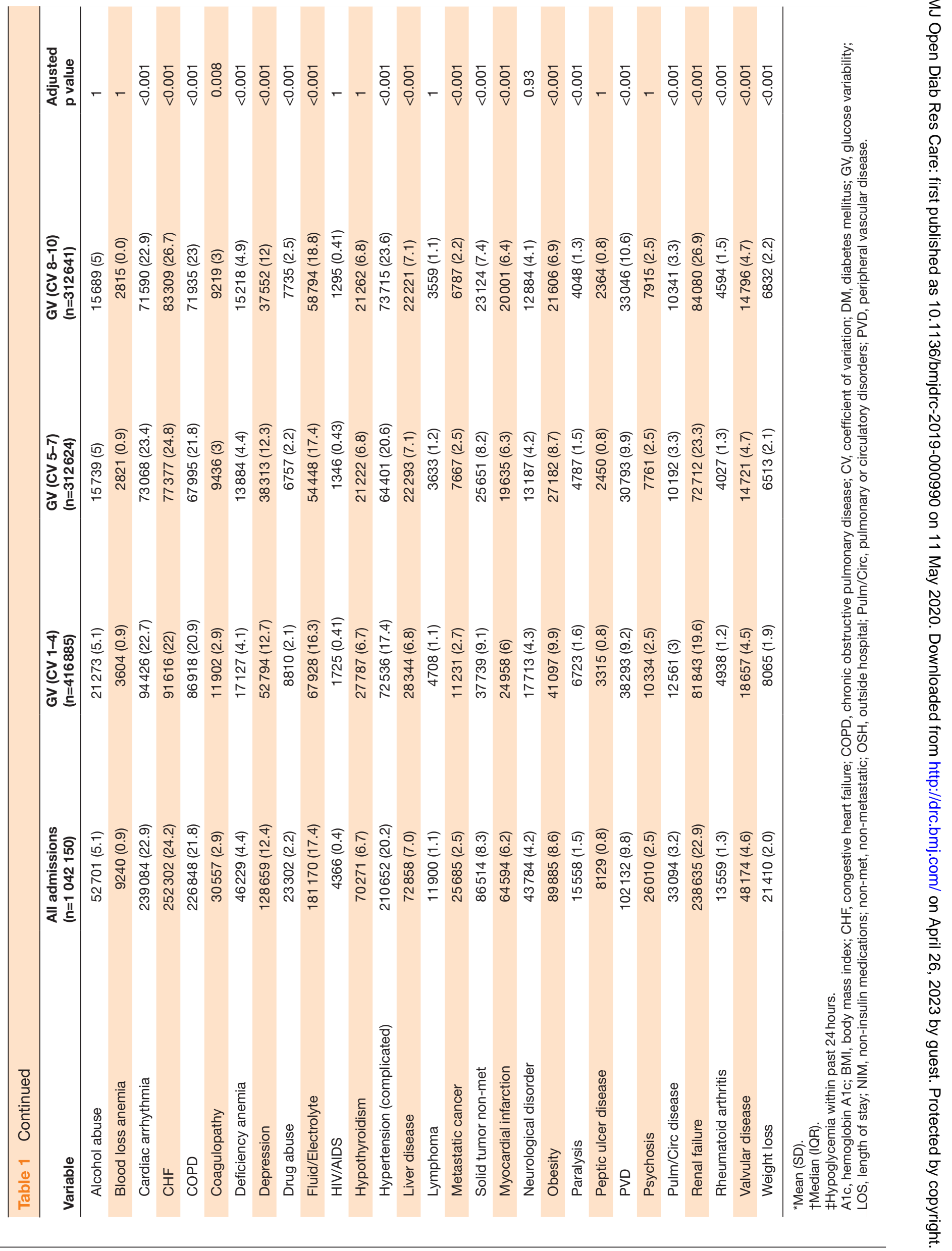


Table 2 Event RR of the 30-day readmission by CV decile category, obtained in the last 24 hours of inpatient stay

\begin{tabular}{|c|c|c|c|c|c|c|}
\hline Decile category: CV\%* & $\begin{array}{l}\text { Model 1: RR } \\
(95 \% \mathrm{Cl})\end{array}$ & $P$ value & $\begin{array}{l}\text { Model 2: RR } \\
(95 \% \mathrm{Cl})\end{array}$ & $P$ value & $\begin{array}{l}\text { Model 3: RR } \\
(95 \% \mathrm{Cl})\end{array}$ & $P$ value \\
\hline 1st: $3.6(2.0-4.9)$ & 1.00 ref & & 1.00 ref & & 1.00 ref & \\
\hline 2nd: 8.2 (7.2-9.2) & 1.00 (0.98 to 1.02$)$ & 0.88 & 1.00 (0.98 to 1.02$)$ & 0.81 & 1.00 (0.98 to 1.02$)$ & 0.80 \\
\hline 3rd: $12.0(11.1-12.9)$ & $1.02(1.00$ to 1.04$)$ & 0.06 & 1.01 (0.99 to 1.03$)$ & 0.44 & 1.01 (0.99 to 1.03$)$ & 0.45 \\
\hline 4th: $15.6(14.7-16.5)$ & $1.03(1.01$ to 1.05$)$ & 0.0004 & 1.01 (0.99 to 1.03$)$ & 0.25 & 1.01 (0.99 to 1.03$)$ & 0.27 \\
\hline 5th: 19.4 (18.4-20.3) & 1.06 (1.04 to 1.08$)$ & $<0.0001$ & 1.02 (1.00 to 1.04$)$ & 0.03 & $1.02(1.00$ to 1.04$)$ & 0.03 \\
\hline 6th: 23.4 (22.4-24.5) & $1.08(1.06$ to 1.10$)$ & $<0.0001$ & 1.03 (1.01 to 1.05$)$ & 0.002 & $1.03(1.01$ to 1.05$)$ & 0.003 \\
\hline 7th: 28.1 (26.9-29.4) & 1.10 (1.08 to 1.12$)$ & $<0.0001$ & 1.04 (1.02 to 1.06$)$ & $<0.0001$ & $1.04(1.02$ to 1.05$)$ & $<0.0001$ \\
\hline 8th: 33.9 (32.3-35.6) & 1.15 (1.13 to 1.18$)$ & $<0.0001$ & 1.07 (1.05 to 1.09$)$ & $<0.0001$ & 1.07 (1.05 to 1.09$)$ & $<0.0001$ \\
\hline 9th: 41.8 (39.5-44.4) & $1.16(1.13$ to 1.19$)$ & $<0.0001$ & 1.07 (1.04 to 1.09$)$ & $<0.0001$ & $1.06(1.03$ to 1.08$)$ & $<0.0001$ \\
\hline 10th: 56.2 (51.2-64.1) & $1.23(1.20$ to 1.26$)$ & $<0.0001$ & 1.10 (1.08 to 1.13$)$ & $<0.0001$ & 1.08 (1.05 to 1.10$)$ & $<0.0001$ \\
\hline
\end{tabular}

Model 1: adjusting for age, gender, race.

Model 2: adjusting for age, gender, race (model 1) and length of stay, DM medication groups, income, BMI, year of admission, admission source, admitting service, comorbidities.

Model 3: adjusting for age, gender, race, length of stay, DM medication groups, income, BMI, year of admission, admission source, admitting service, comorbidities (model 2) and hypoglycemia.

In bold are $\mathrm{p}<0.05$ considered to be statistically signifficant.

${ }^{*}$ Median (IQR).

$\mathrm{BMI}$, body mass index; CV, coefficient of variation; DM, diabetes mellitus; $\mathrm{RR}$, rate ratio.

increase in the 30-day readmission rate compared with those in the first CV category. In model 2, in which we adjusted for almost all covariates that we collected (except for hypoglycemia), admissions with $\mathrm{CV}$ in the 5th-10th CV categories had a statistically significant progressive increase in the 30-day readmission rate. The results were similar in model 3 , where we adjusted for all the variables in model 2 and included hypoglycemia. Overall, compared with the reference 1st CV category, after adjusting for all the covariates, admissions with the highest $\mathrm{CV}$ values in the 10th category had an increased 30-day readmission rate (model 3, RR: 1.08 (95\% CI 1.05 to 1.10$), \mathrm{p}<0.0001)$.

Similarly, when we used SD as a measurement of glucose variability (table 3 ), admissions with $\mathrm{SD}$ in the 3rd-10th categories (models 1 and 2) and admissions with SD in the 4th-10th categories (model 3) had a higher 30-day readmission rate compared with the 1 st SD category. After adjusting for all the covariates including hypoglycemia (model 3), admissions with the SD values

Table 3 Event RR of the 30 -day readmission by SD decile category, obtained in the last 24 hours of inpatient stay

\begin{tabular}{|c|c|c|c|c|c|c|}
\hline $\begin{array}{l}\text { Decile category: } \\
\text { SD mg/dL* }\end{array}$ & $\begin{array}{l}\text { Model 1: RR } \\
(95 \% \mathrm{Cl})\end{array}$ & $P$ value & $\begin{array}{l}\text { Model 2: } \\
\text { RR }(95 \% \mathrm{Cl})\end{array}$ & $P$ value & $\begin{array}{l}\text { Model 3: } \\
\text { RR (95\% Cl) }\end{array}$ & $P$ value \\
\hline 1st: $5.1(2.8-7.1)$ & $1.00 \mathrm{ref}$ & & $1.00 \mathrm{ref}$ & & $1.00 \mathrm{ref}$ & \\
\hline 2nd: 12.1 (10.6-13.7) & 1.02 (0.99 to 1.04$)$ & 0.16 & 1.00 (0.99 to 1.03 ) & 0.55 & 1.01 (0.99 to 1.03$)$ & 0.59 \\
\hline 3rd: 18.4 (16.8-19.8) & 1.04 (1.02 to 1.07 ) & 0.0002 & $1.02(1.00$ to 1.04$)$ & 0.049 & 1.02 (1.00 to 1.04$)$ & 0.07 \\
\hline 4th: 24.5 (22.9-26.2) & 1.08 (1.06 to 1.10$)$ & $<0.0001$ & 1.04 (1.02 to 1.06 ) & $<0.0001$ & 1.04 (1.02 to 1.06$)$ & $<0.0001$ \\
\hline 5th: $31.1(29.5-33.0)$ & 1.10 (1.07 to 1.12$)$ & $<0.0001$ & 1.05 (1.03 to 1.07 ) & $<0.0001$ & 1.04 (1.02 to 1.06$)$ & $<0.0001$ \\
\hline 6th: $38.7(36.7-40.7)$ & 1.11 (1.08 to 1.13$)$ & $<0.0001$ & 1.05 (1.02 to 1.07 ) & $<0.0001$ & 1.04 (1.02 to 1.06$)$ & 0.0001 \\
\hline 7th: $47.6(45.3-50.2)$ & 1.14 (1.12 to 1.16$)$ & $<0.0001$ & 1.07 (1.05 to 1.09 ) & $<0.0001$ & 1.06 (1.04 to 1.08$)$ & $<0.0001$ \\
\hline 8th: $59.1(55.9-62.6)$ & 1.15 (1.13 to 1.18 ) & $<0.0001$ & 1.07 (1.04 to 1.09 ) & $<0.0001$ & 1.06 (1.04 to 1.09$)$ & $<0.0001$ \\
\hline 9th: 75.7 (70.7-81.4) & 1.20 (1.17 to 1.23$)$ & $<0.0001$ & 1.10 (1.07 to 1.12 ) & $<0.0001$ & 1.09 (1.06 to 1.11$)$ & $<0.0001$ \\
\hline 10th: 109.6 (97.3-129.6) & 1.27 (1.23 to 1.30$)$ & $<0.0001$ & $1.13(1.10$ to 1.15$)$ & $<0.0001$ & 1.11 (1.09 to 1.14$)$ & $<0.0001$ \\
\hline
\end{tabular}

Model 1: adjusting for age, gender, race.

Model 2: adjusting for age, gender, race (model 1) and length of stay, DM medication groups, income, BMI, year of admission, admission source, admitting service, comorbidities.

Model 3: adjusting for age, gender, race, length of stay, DM medication groups, income, BMI, year of admission, admission source, admitting service, comorbidities (model 2) and hypoglycemia.

In bold are $\mathrm{p}<0.05$ considered to be statistically signifficant.

${ }^{*}$ Median (IQR).

$\mathrm{BMI}$, body mass index; DM, diabetes mellitus; RR, rate ratio. 
in the 10th category had the highest 30 -day readmission rate (RR: 1.11 (95\% CI 1.09 to 1.14 ), $\mathrm{p}<0.0001)$.

\section{DISCUSSION}

In this study, we evaluated the association of GV during the last 24 hours of hospitalization with 30-day readmission rates among a large cohort of adults with diabetes admitted in the non-critical care setting. We identified that admissions of patients with DM with the highest GV during the last 24 hours of the inpatient stay, using CV and SD measurements, had an increased risk for 30-day readmission. This association persisted despite adjustment for multiple covariates, notably including adjustment for hypoglycemia during the last 24 hours of hospitalization.

Evidence from studies performed in the outpatient setting has shown that higher GV increases risk of adverse clinical outcomes. The effect of GV on oxidative stress and endothelial dysfunction is thought to be equal or greater than that attributed to persistent hyperglycemia, and is postulated to contribute to the development of microvascular and macrovascular DM complications. ${ }^{23}$ Within the inpatient setting several studies have examined increased GV with adverse outcomes, revealing associations with prolonged length of stay ${ }^{19}$ and increased mortality in both ICU and non-critical care settings. ${ }^{195-38}$

To our knowledge, this is the first nationwide study aiming to determine whether increased GV is associated with increased risk for hospital readmissions. Hospital readmissions within 30 days postdischarge has drawn national attention with federal policy reform due to the rising healthcare expenditure, high prevalence and preventability. ${ }^{1}$ Therefore, research focused on exploring potentially modifiable factors to reduce readmissions is of utmost importance. The effect of glucose control at admission or throughout the inpatient stay on readmission has been evaluated, ${ }^{18}$ but not during the final day of the hospitalization. Recently, we have reported an association of lower glucose values on the last inpatient day with increased rate of 30 -day readmission. ${ }^{26}$ In the present analysis, we have additionally showed an independent association of higher GV on the last day of hospitalization with increased 30-day readmission. The results from our cohort studies may shed light on two potentially modifiable risk factors for reducing 30-day readmissions.

It is unknown how higher GV on the last day of hospitalization may contribute to increased risk of 30-day readmission. Although we did not have access to postdischarge glycemic values, one potential explanation is that high GV predisposes patients to postdischarge hypoglycemia or to significant hyperglycemia, which may lead to readmission. In our study, we found that those admissions of patients with the highest GV also had the highest incidence of hypoglycemia during the last 24 hours of the hospital stay, which is consistent with previous observations. It is known that blood glucose disturbances precede severe hypoglycemia ${ }^{39}$ and increased GV has been previously identified as a predictor of hypoglycemia. ${ }^{254041}$ The transition of care from inpatient to the outpatient setting signifies a vulnerable and challenging time with greater risk of dysglycemia, as well as healthcare utilization such as emergency room visits or readmissions. ${ }^{2642} 43$ As patients with DM have multiple and often suboptimally controlled comorbidities, they have an inherently higher risk for frequent readmissions. ${ }^{3244}$

Despite the growing evidence of an association of GV with poor clinical outcomes, it remains debatable whether GV should be considered a treatment target. ${ }^{45-47}$ Lack of standardization for the definition and method of measurement of GV contributes to this uncertainty. Within the literature there is significant heterogeneity of GV indices reported, ${ }^{24}$ therefore the consolidation of the available evidence to drive changes in clinical practice is difficult. SD, a simple method for assessing GV, represents the distribution of data around the mean blood glucose, ${ }^{23}$ and is useful for analysis of intraday variation of POC glucose values. Other metrics of variability have been proposed including but not limited to J-index, mean amplitude of glucose excursion, mean absolute glucose, continuous overlapping net glycemic action, the high and low blood glucose index and mean of daily differences. ${ }^{22} 2325$ A criticism of the $\mathrm{CV}$ is that the mean is used in its calculation and as a result, violations of normality of the distribution of glucose values or extreme concentrations can exaggerate the CV measurement. Although this is a valid criticism, each of the other metrics have their own limitations. ${ }^{23}$ We used the CV which has been frequently reported. ${ }^{19} 35$ Although an imperfect metric of variability, our study shows that the $\mathrm{CV}$ is related to 30-day readmission and suggests further studies should be conducted to determine if reducing variability lowers the rate of readmission. Recently, it has been advocated that continuous glucose monitoring in the hospital may offer advantages over POC glucose testing in managing and evaluating glycemic control in hospitalized patients. ${ }^{48}$ Future studies using this technology will help us to confirm our findings on the importance of GV on hospital outcome and readmission risk.

Our study has several strengths. To our knowledge, this cohort is one of the largest studies evaluating readmission rates in patients with DM using national data. Additionally, the VA Healthcare System is a 'closed' health system where most veterans receive all of their healthcare including treatment during hospitalizations thus assuring a robust method to accurately measure readmissions. Given the comprehensive and extensive nature of the Veterans Health Administration data sources, we were able to include data for $>1$ million admissions of patients with diabetes and a broad set of covariates and risk factors in this analysis (table 1 ).

There are limitations to our study that should be considered. Consistent with previously published studies using Veterans Health Administration data sources, our analysis is restricted to this single healthcare system. ${ }^{27}$ Although we included nationwide data, it excluded readmissions to non-VA hospitals. Additionally, our patient population 
may not be representative of the general population given veterans are more likely to be male, elderly and have multiple comorbid conditions. However, since we adjusted for social-demographic data and comorbidities, we have minimized the impact of these differences and we believe the results can be extrapolated to the general DM population. Glucose variability can be influenced by the nutritional intake during an inpatient stay, which was not collected in our study, and perhaps is a limitation. We did not distinguish the preventable readmissions from other readmissions. Although preventability of readmissions has been evaluated using administrative data previously, it is subjective and therefore may not represent the most optimal method to study this objective. ${ }^{27} 49$ Identifying high GV as a potentially modifiable risk factor in the last 24 hours using POC glucose values alone may be challenging. Methods in detecting high GV in the inpatient setting in a reliable and efficient way need to be explored. Consideration of CGM use in the hospital setting would ensure collection of accurate glucometric data, including CV and SD. Current ongoing prospective studies using CGM technology are investigating the use of CGM in the hospital setting and after discharge, and should provide more comprehensive information regarding GV on clinical outcomes and readmission risk. Lastly, we limited our analysis on the effect of GV during the last day of the hospitalization on readmission and did not examine the overall effect during the entire hospital stay.

In conclusion, the results of this VA nationwide cohort observation study including 1042150 admissions of patients with DM indicate that patients with higher GV on the last day of hospitalization were at a higher risk for 30-day readmission. Although the increased 30-day readmission risk could also be secondary to underlying medical conditions, inpatient diabetes medications or other risk factors unrelated to glucose variability, our extensive analyses, adjusting for multiple covariates indicate that increased GV during the last day of the hospitalization can be considered as a potential risk factor for early readmission. Further prospective studies are needed to fully explore whether reducing GV can decrease the risk for 30-day readmission.

\section{Author affiliations}

${ }^{1}$ Division of Endocrinology, Baltimore Veterans Affairs Medical Center, Baltimore, Maryland, USA

${ }^{2}$ Division of Endocrinology, Diabetes, and Nutrition, University of Maryland School of Medicine, Baltimore, Maryland, USA

${ }^{3}$ Laboratory of Experimental Endocrinology, University of Crete School of Medicine, Heraklion, Greece

${ }^{4}$ Division of Nephrology, University of Maryland School of Medicine, Baltimore, Maryland, USA

${ }^{5}$ Baltimore Veterans Affairs Medical Center GRECC (Geriatric Research, Education, and Clinical Center), Baltimore, Maryland, USA

${ }^{6}$ Georgetown University School of Medicine; MedStar Diabetes, Research and Innovation Institutes, Washington, DC, USA

${ }^{7}$ Department of Medicine, University of Maryland School of Medicine, Baltimore, Maryland, USA
${ }^{8}$ Department of Epidemiology and Public Health, University of Maryland, Baltimore, Maryland, USA

${ }^{9}$ Division of Endocrinology, Metabolism, and Lipids, Emory University School of Medicine, Atlanta, Georgia, USA

Contributors EKS and MZ had full access to all the data in the study and take responsibility for the integrity of the data and the accuracy of the data analysis. EKS conceived and designed the study, provided guidance for the statistical analysis and wrote the manuscript. GEU made critical revisions to the study design and manuscript and takes responsibility for the integrity of the data and the accuracy of the data analysis. MZ performed the statistical analyses and made critical revisions to the manuscript for important intellectual content. LGS, TS, JDS, GN, JCF and MFM made critical revisions to the manuscript for important intellectual content. The authors had access to all the study data and take full responsibility of the accuracy of the analysis. All authors approved the manuscript.

Funding This work was supported in part by the VA MERIT award (\#1101CX001825-01) from the US Department of Veterans Affairs Clinical Sciences Research and Development Service (EKS) and by the Baltimore VA Patient Safety Center of Inquiry (JCF). MFM has received research support from the National Institutes of Health for an inpatient diabetes education study (R34 Planning Grant for Pragmatic Research in Healthcare settings, DK-109503, entitled Diabetes To Go Inpatient). JDS was supported by National Institute of Aging (NIA P30-AG028747), National Institute of Diabetes and Digestive and Kidney Disease (NIDDK P30DK072488) and the Baltimore VA Geriatric Research, Education and Clinical Center. GEU is partly supported by research grants from the National Center for Advancing Translational Sciences of the National Institutes of Health under Award Number UL1TR002378, from the Clinical and Translational Science Award program and from the National Institute of Diabetes and Digestive and Kidney Disease (NIDDK P30DK11102).

Disclaimer The funders had no role in the design or the conduction of the study; collection, analysis, interpretation of the data; preparation, review, approval of the manuscript and decision to submit the manuscript for publication.

Competing interests EKS has received research support from DEXCOM for the conduction of clinical studies, which did not support this work monetarily or in kind. MFM has recently completed an Eli Lilly funded outpatient Pharma trial, which did not support this work monetarily or in kind. GEU has received unrestricted research support for inpatient studies (to Emory University) from Sanofi, Novo Nordisk, and Dexcom, which did not support the work monetarily or in kind.

Patient consent for publication Not required.

Ethics approval This study was approved by the University of Maryland Institutional Review Board and the Baltimore VA Research and Development Committee.

Provenance and peer review Not commissioned; externally peer reviewed.

Data availability statement Data are available in a public, open access repository. Data are available on reasonable request. This nationwide cohort study used data obtained from the Veterans Affairs (VA) health system, data that are publicly available on request.

Open access This is an open access article distributed in accordance with the Creative Commons Attribution Non Commercial (CC BY-NC 4.0) license, which permits others to distribute, remix, adapt, build upon this work non-commercially, and license their derivative works on different terms, provided the original work is properly cited, appropriate credit is given, any changes made indicated, and the use is non-commercial. See: http://creativecommons.org/licenses/by-nc/4.0/.

\section{ORCID iDs}

Elias K Spanakis http://orcid.org/0000-0002-9352-7172

Michelle F Magee http://orcid.org/0000-0002-4692-3201

Guillermo E Umpierrez http://orcid.org/0000-0002-3252-5026

\section{REFERENCES}

1 Rubin DJ. Hospital readmission of patients with diabetes. Curr Diab Rep 2015;15:17.

2 Kocher RP, Adashi EY. Hospital readmissions and the Affordable care act: Paying for coordinated quality care. JAMA 2011;306:1794-5.

3 Chen JY, Ma Q, Chen H, et al. New bundled world: quality of care and readmission in diabetes patients. J Diabetes Sci Technol 2012;6:563-71. 
4 Robbins JM, Webb DA. Diagnosing diabetes and preventing rehospitalizations: the urban diabetes study. Med Care 2006;44:292-6.

5 Bennett KJ, Probst JC, Vyavaharkar M, et al. Lower rehospitalization rates among rural Medicare beneficiaries with diabetes. J Rural Health 2012;28:227-34.

6 Albrecht JS, Hirshon JM, Goldberg R, et al. Serious mental illness and acute Hospital readmission in diabetic patients. Am J Med Qual 2012;27:503-8.

7 Healy SJ, Black D, Harris C, et al. Inpatient diabetes education is associated with less frequent Hospital readmission among patients with poor glycemic control. Diabetes Care 2013;36:2960-7.

8 Jiang HJ, Andrews R, Stryer D, et al. Racial/Ethnic disparities in potentially preventable readmissions: the case of diabetes. Am J Public Health 2005;95:1561-7.

9 Ostling S, Wyckoff J, Ciarkowski SL, et al. The relationship between diabetes mellitus and 30-day readmission rates. Clin Diabetes Endocrinol 2017;3:3.

10 Rubin DJ, Handorf EA, Golden SH, et al. Development and validation of a novel tool to predict Hospital readmission risk among patients with diabetes. Endocr Pract 2016;22:1204-15.

11 Enomoto LM, Shrestha DP, Rosenthal MB, et al. Risk factors associated with 30-day readmission and length of stay in patients with type 2 diabetes. J Diabetes Complications 2017;31:122-7.

12 Phillips RS, Safran C, Cleary PD, et al. Predicting emergency readmissions for patients discharged from the medical service of a teaching hospital. J Gen Intern Med 1987;2:400-5.

13 Ferraris VA, Ferraris SP, Harmon RC, et al. Risk factors for early Hospital readmission after cardiac operations. J Thorac Cardiovasc Surg 2001;122:278-86.

14 Stewart RD, Campos CT, Jennings B, et al. Predictors of 30-day Hospital readmission after coronary artery bypass. Ann Thorac Surg 2000;70:169-74.

15 American Diabetes Association. Economic costs of diabetes in the U.S. in 2017. Diabetes Care 2018;41:917-28.

16 American Diabetes Association. Economic costs of diabetes in the U.S. in 2012. Diabetes Care 2013;36:1033-46.

17 Karunakaran A, Zhao H, Rubin DJ. Predischarge and Postdischarge risk factors for hospital readmission among patients with diabetes. Med Care 2018;56:634-42.

18 Zapatero A, Gómez-Huelgas R, González N, et al. Frequency of hypoglycemia and its impact on length of stay, mortality, and shortterm readmission in patients with diabetes hospitalized in internal medicine wards. Endocr Pract 2014;20:870-5.

19 Mendez CE, Mok K-T, Ata A, et al. Increased glycemic variability is independently associated with length of stay and mortality in noncritically ill hospitalized patients. Diabetes Care 2013;36:4091-7.

20 Kim Y, Rajan KB, Sims SA, et al. Impact of glycemic variability and hypoglycemia on adverse hospital outcomes in non-critically ill patients. Diabetes Res Clin Pract 2014;103:437-43.

21 Monnier L, Mas E, Ginet C, et al. Activation of oxidative stress by acute glucose fluctuations compared with sustained chronic hyperglycemia in patients with type 2 diabetes. JAMA 2006;295:1681-7

22 DeVries JH. Glucose variability: where it is important and how to measure it. Diabetes 2013;62:1405-8.

23 Frontoni S, Di Bartolo P, Avogaro A, et al. Glucose variability: an emerging target for the treatment of diabetes mellitus. Diabetes Res Clin Pract 2013;102:86-95.

24 Eslami S, Taherzadeh Z, Schultz MJ, et al. Glucose variability measures and their effect on mortality: a systematic review. Intensive Care Med 2011;37:583-93.

25 Siegelaar SE, Holleman F, Hoekstra JBL, et al. Glucose variability; does it matter? Endocr Rev 2010;31:171-82.

26 Spanakis EK, Umpierrez GE, Siddiqui T, et al. Association of glucose concentrations at hospital discharge with readmissions and mortality: a nationwide cohort study. J Clin Endocrinol Metab 2019;104:3679-91.
27 Kaboli PJ, Go JT, Hockenberry J, et al. Associations between reduced Hospital length of stay and 30-day readmission rate and mortality: 14-year experience in 129 Veterans Affairs hospitals. Ann Intern Med 2012;157:837-45.

28 Miller DR, Safford MM, Pogach LM. Who has diabetes? Best estimates of diabetes prevalence in the Department of Veterans Affairs based on computerized patient data. Diabetes Care 2004;27 (Suppl 2):B10-21.

29 Elixhauser A, Steiner C, Harris DR, et al. Comorbidity measures for use with administrative data. Med Care 1998;36:8-27.

30 Umpierrez GE, Hellman R, Korytkowski MT, et al. Management of hyperglycemia in hospitalized patients in non-critical care setting: an endocrine Society clinical practice guideline. J Clin Endocrinol Metab 2012;97:16-38.

31 Jencks SF, Williams MV, Coleman EA. Rehospitalizations among patients in the Medicare fee-for-service program. N Engl J Med 2009;360:1418-28.

32 Jiang HJ, Stryer D, Friedman B, et al. Multiple hospitalizations for patients with diabetes. Diabetes Care 2003;26:1421-6.

33 Zeger SL, Liang KY. Longitudinal data analysis for discrete and continuous outcomes. Biometrics 1986;42:121-30.

34 Liang K-YEE, Zeger SL. Longitudinal data analysis using generalized linear models. Biometrika 1986;73:13-22.

35 Akirov A, Diker-Cohen T, Masri-Iraqi H, et al. High glucose variability increases mortality risk in hospitalized patients. J Clin Endocrinol Metab 2017;102:2230-41.

36 Hermanides J, Vriesendorp TM, Bosman RJ, et al. Glucose variability is associated with intensive care unit mortality. Crit Care Med 2010;38:838-42.

37 Egi M, Bellomo R, Stachowski E, et al. Variability of blood glucose concentration and short-term mortality in critically ill patients. Anesthesiology 2006;105:244-52.

38 Krinsley JS. Glycemic variability: a strong independent predictor of mortality in critically ill patients. Crit Care Med 2008;36:3008-13.

39 Kovatchev BP, Cox DJ, Farhy LS, et al. Episodes of severe hypoglycemia in type 1 diabetes are preceded and followed within 48 hours by measurable disturbances in blood glucose. $J$ Clin Endocrinol Metab 2000;85:4287-92.

40 Kudva YC, Basu A, Jenkins GD, et al. Glycemic variation and hypoglycemia in patients with well-controlled type 1 diabetes on a multiple daily insulin injection program with use of glargine and ultralente as basal insulin. Endocr Pract 2007;13:244-50.

41 Saudek CD, Duckworth WC, Giobbie-Hurder A, et al. Implantable insulin pump vs multiple-dose insulin for non-insulin-dependent diabetes mellitus: a randomized clinical trial. Department of Veterans Affairs implantable insulin pump Study Group. JAMA 1996;276:1322-7.

42 Umpierrez GE, Reyes D, Smiley D, et al. Hospital discharge algorithm based on admission $\mathrm{HbA1c}$ for the management of patients with type 2 diabetes. Diabetes Care 2014;37:2934-9.

43 Forster AJ, Murff HJ, Peterson JF, et al. Adverse drug events occurring following hospital discharge. J Gen Intern Med 2005;20:317-23.

44 Umpierrez GE, Isaacs SD, Bazargan N, et al. Hyperglycemia: an independent marker of in-hospital mortality in patients with undiagnosed diabetes. J Clin Endocrinol Metab 2002;87:978-82.

45 Monnier L, Colette C, Wojtusciszyn A, et al. Toward defining the threshold between low and high glucose variability in diabetes. Diabetes Care 2017;40:832-8.

46 Ceriello A, Kilpatrick ES. Glycemic variability: both sides of the story. Diabetes Care 2013;36 (Suppl 2):S272-5.

47 Bergenstal RM. Glycemic variability and diabetes complications: does it matter? simply put, there are better glycemic markers! Diabetes Care 2015;38:1615-21.

48 Wang M, Singh LG, Spanakis EK. Advancing the use of CGM devices in a Non-ICU setting. J Diabetes Sci Technol 2019;13:674-81.

49 Goldfield NI, McCullough EC, Hughes JS, et al. Identifying potentially preventable readmissions. Health Care Financ Rev 2008;30:75-91. 